\title{
RELIABILITY EVALUATION AS A MEANS OF INCREASING THE EFFICIENCY OF EQUIPMENT MAINTENANCE
}

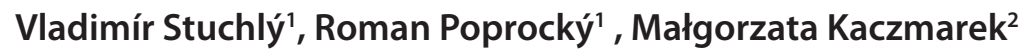 \\ 1 University of Žilina, Faculty of Mechanical Engineering, Univerzitna 1, 010 26, Žilina, Slovakia, e-mail: vladimir. \\ stuchly@fstroj.uniza.sk, roman.poprocky@fstroj.uniza.sk \\ 2 Poznan University of Technology, Faculty of Management Engineering, Strzelecka St. 11, 60-965 Poznań \\ Poland, e-mail: malgorzata.jasiulewicz-kaczmarek@put.poznan.pl
}

Received: 2016.08.31

Accepted: 2016.10.08

Published: 2016.12.01

\begin{abstract}
Quality assurance of production and the associated maintenance systems have changed a lot for recent decades and are subject to change requirements for reliability - Reliability and Availability of machinery and equipment subject to the optimal maintenance costs. The paper deals with design options and assessment of the maintenance system intended method of reliability-oriented maintenance and maintenance costs. They use the methods of statistical and probabilistic analyzes of data on failure mode of operation, as well as methods priori reliability. The emphasis is on cost-effectiveness evaluation.
\end{abstract}

Keywords: reliability model, centred maintenance, cost, consequences.

\section{INTRODUCTION}

In traditional maintenance approach the requirements on maintenance of each component were determined in accordance with its actual or assumed technical characteristics, without considering its failure consequences. The resulting schedules were used to all similar objects without considering different consequences coming from different operational contexts.

For utilization of reliability parameters in machines and equipment maintenance it is necessary to answer also the questions such as:

- How the reliability parameters can be found out?

- Is there a reason for their determination?

- Is there a reason to investigate components or the whole systems?

- Which reliability parameters have the main importance for maintenance? And do they have any importance?

- How, when, where and in what extent should these reliability parameters be determined?
- How can the calculation of reliability parameters help at creation of maintenance systems?

Reliability of already operated machines and equipment (because these are in the focus of maintenance) was built in during the design and manufacture phase. Maintenance itself can not improve the built in (inherent) reliability. Then for overall quality of machines and equipment it should be distinguished [1].

Reliability, the decisive quality characteristic of a product:

- Design quality: ability of structure to fulfil the user requirements (also known as technical level).

- Production quality: measure of product quality compliance in the moment of output check with quality prescribed in technical documentation.

- Utilisation quality: functional quality of a product under given working conditions. 
From long-term experience in engineering it is evident that the machines reliability can be improved by:

- Selection of better (but more expensive) components,

- Increase of reliability of functionally linked components,

- Reducing the number of components that are functional in series (serial systems),

- By redundancy (component or total) of less reliable components,

- Running-in, avoiding the initial failures,

- By protection against damaging effects (trained operators, suitable operational conditions etc.).

Reliability theory studies rules of failure in objects (in general of machines an equipment) and methods of their prediction, it searches possibilities of increasing reliability of objects in all stages of their designing and utilization. It deals with quantitative reliability parameters, economic and effectiveness characteristics.

In the paper procedures, solutions, reliability calculation methods and their use for maintenance are presented as they were elaborated at the Faculty of Mechanical Engineering, University of Zilina.

\section{STATISTICAL AND PARAMETRIC RELIABILITY OF ELEMENTS}

In the reliability theory we look at failures in a mathematical-statistical way as random phenomena because we are not able to reliably determine in advance the moment of occurrence of a failure and its extent because of the complexity of phenomena related to failure. Reliability analyses are conducted especially in the stage of concept definition, in the stage of designing and development and I the stage of operation and maintenance on different levels of structure breakdown for evaluation and estimation of reliability parameters of an object (element or system).

Analytic methods enable evaluation of qualitative characteristics and estimate parameters (for example failure rate, MTTF, MTBF, reliability probability (failure-free operation), coefficients of stabile availability) that characterise predicted long-term operational behaviour of objects. To ensure proper elaboration of complex or multi function systems it can be necessary to consider several complementary analytical methods. Among complementary actions there are: investigation of a system, determination of week points and unbalances, critical or high risky failure modes, consideration problems of system interfaces, failsafe abilities and mechanisms etc. Development of alternative methods for reliability improvement (for example distribution of requirements on redundancy, monitoring of parameters, failure detection, procedures of systems reconfiguration, maintainability, exchangeability of spare parts and procedures of repairs) should be considered as well. For alternative designs elaboration of optimisation studies from the costs and profit point of view and evaluation of proposed designs should be done.

For quantitative evaluation of reliability, criteria (quantitative indicators) were defined and their numerical values for a certain product we call as a reliability characteristic. Long term behaviour in operation of repairable system is very much affected by system maintainability as well as by maintenance strategy. Availability indicator is suitable indicator for evaluation of influence of maintenance on system reliability.

Available stochastic reliability models can be expressed on the base of detailed knowledge of behaviour of given set of objects in operation. They must enable generalisation of the obtained findings also on other similar objects that were not directly subject of investigation [1].

Implementation of statistic methods has irreplaceable subsystems as follows:

- System of information collection on operational reliability;

- System of selection, use and primary analysis of evaluated sample of objects;

- System of quantification of reliability indicators (parameters) of elements of objects;

- System of quantification of object's reliability as a system;

- System of consequent technical analysis and implementation of obtained knowledge in operation, maintenance etc.

The most suitable theoretical model that optimally characterises reliability of engineering products is Weibull model in particular because in its generality covers practically majority of possible courses of random quantities that can occur during solution of objects reliability. Random quantity $\mathrm{X}$ will have Weibull distribution (three parameters).

On this basis 5 fundamental reliability parameters (indicators) are defined: failure probability $\mathrm{Q}(\mathrm{t})$, reliability probability $\mathrm{R}(\mathrm{t})$, failure 


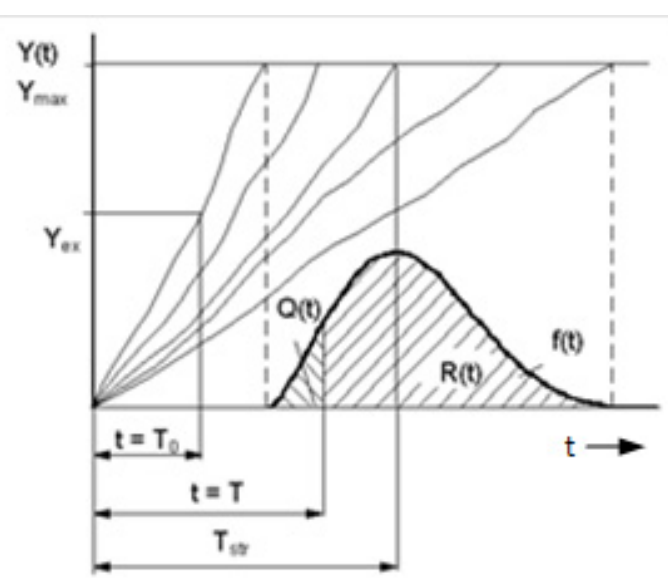

Fig. 1. Forming of time to failure distribution law

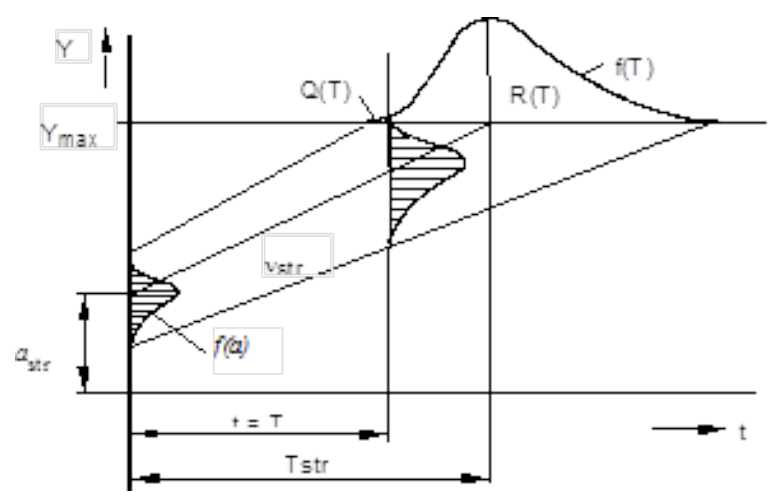

Fig. 2. Model of forming of gradual failure (generalised model) rate $\lambda(t)$, failure density $f(t)$, Mean time to failure. Indicators of parametric reliability are same as for statistic reliability and can be calculated in accordance with the selected model of parameter change course (Fig. 1, Fig. 2).

For calculations of indicators of parametric reliability, it is necessary to determine equation of parameter change with initial value and regression coefficient as a velocity of its change by use of suitable method. Models and calculation of $\mathrm{R}(\mathrm{T})$ are presented in Table 1 [1].

Additional work load from data evaluation because of their extent, what nowadays cannot be done without information technology and in most cases it is again question of information system, automation of data collection, etc.

However, information collection can not be done for all machines and equipment and there must be criteria for selection of critical equipment. Analysis of operational and maintenance information reveals criticality of equipment from the point of view of production losses, maintenance costs, availability and low value of Tstr (MTTF).

Proposal of maintenance system can be divided into the individual steps:

1. Determination of reliability indicators of components.

2. Determination of the optimal times (intervals) of components operation between carrying out the planned maintenance work. This is

Table 1. Formulae for calculation of parametric reliability according to equation of parameter change course

\begin{tabular}{|c|c|c|}
\hline \multicolumn{2}{|r|}{ Equation of parameter change course } & Reliability probability (probability of failure-free operation) \\
\hline $1 .+2$ & $Y(T)=a+k \cdot t$ & $R(T)=0.5+\Phi\left(\frac{Y_{\max }-Y_{0}-v_{s t r} \cdot T}{T \cdot \sigma_{v}}\right)$ \\
\hline 3. & $Y(T)=a_{s t r}+k \cdot t$ & $R(T)=0.5+\Phi\left(\frac{Y_{\max }-a_{s t r}-v \cdot T}{\sigma_{a}}\right)$ \\
\hline 4. & $Y(T)=a \cdot \exp \left(-v_{x} \cdot t\right)$ & $R(T)=0.5+\Phi\left(\frac{\ln Y_{0}-\ln Y_{\max }-v_{x s t r} \cdot T}{T \cdot \sigma_{v_{x}}}\right)$ \\
\hline 5. & $Y(T)=a_{s t r}+k \cdot t$ & $R(T)=0.5+\Phi\left(\frac{\ln Y_{0}-\ln Y_{\max }-v_{x} \cdot T}{\sigma_{a}}\right)$ \\
\hline 6. & $Y(T)=a_{s t r}+k \cdot t$ & $R(T)=0.5+\Phi\left(\frac{Y_{\max }-Y_{0}-v_{s t r} \cdot T}{\sqrt{\sigma_{a}^{2}+\sigma_{v}^{2} \cdot T^{2}}}\right)$ \\
\hline
\end{tabular}


based on component's reliability and costs for preventive and corrective maintenance works.

3. Proposal of the maintenance system. This is based on determined times (intervals) of components' operation and corresponding maintenance costs.

\section{OPTIMISATION RELIABILITY MODEL OF MAINTENANCE INTERVALS}

Time to repair can be determined for components reliability of which we know, by different approach for statistic or for parametric reliability.

To ensure the required reliability level, planned preventive repairs are carried out after predetermined mileage $\mathrm{L}(\mathrm{km})$ run? During these repairs preventive works, failure finding and restoring of failed components. For simplifying the mathematical model we assume that duration of repair is small compared to up-time (operation without failures).

Because of carrying out the repairs operation time of components will have a cut distribution f'(l) with mean value L'str . Value L'str depends on degree of cut, that is value of selected interval between repairs L (Fig. 3).

Probability of failure of a component during the interval $\mathrm{L}(\mathrm{km})$, that is probability of corrective (unplanned) repair of the component is [1].

The task of determination of optimum interval between repairs leads to determination of such an interval $L$ between planned repairs in which the total costs for keeping objects in failure-free state will be minimum.

We will determine overall costs connected with restoring failed components of $i$-th subsystem during the interval L' $(\mathrm{km})$; for this we will use designation:

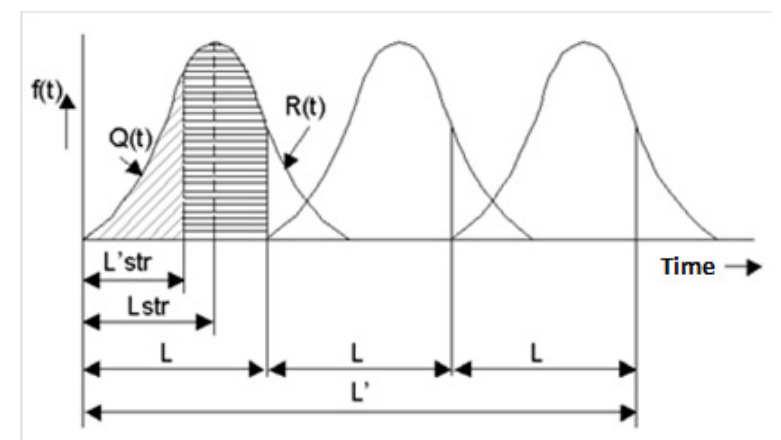

Fig. 3. Interval between repairs L
$\mathrm{C}_{\mathrm{N}}$ - mean value of costs connected with restoring of failed component of $i$-th subsystem in corrective repair when besides costs for repair itself the production and other induced losses should be included.

$\mathrm{C}_{\mathrm{P}}$ - mean value of costs of component of $\mathrm{i}$-th subsystem in preventive repair.

After using this designation for mean values, the costs for maintenance in intervals L' $(\mathrm{km})$ will be calculated using the following formula in such a way that $\mathrm{M}$ is a mean value of costs for restoring of one component of $i$-th subsystem for the interval Lstr $(\mathrm{km})$ in the ratio of costs for preventive and corrective maintenance:

$$
M=\frac{\int_{0}^{\infty} R(l) \cdot d l}{\int_{0}^{L} R(l) \cdot d l} \cdot[1-(1-p) \cdot R(L)]
$$

where: $\mathrm{p}=\mathrm{CP} / \mathrm{CN}-$ ratio of costs for components maintenance in preventive (planned) to corrective maintenance. Condition $\mathrm{CP} /$ $\mathrm{CN}$ is assumed; then values of $\mathrm{p}$ is within the interval $0<\mathrm{p} * 1$.

From (1) it concludes that $\mathrm{M}$ is function of selected interval between repairs $L$ and depend on the type and parameters of distribution of time to failure and also on ration of costs $p$. For analysis of solution of function $M$ it is necessary to fund analytical expression for various types (most commonly used) of distribution of time to repair.

For Weibull distribution [7]:

$$
M=\frac{\Gamma\left(1+\frac{1}{b}\right) \cdot\left[1-(1-p) \cdot e^{-\vartheta_{e}^{b}}\right]}{\int_{0}^{\frac{L}{a}} e^{-\vartheta_{e}^{b}} \cdot d \vartheta_{e}}
$$

For analysis of the formula (5) we use graphic interpretation of $U=v(* e, p, b)$ in the Figure 4 for $\mathrm{b}=3.43$ and for various values of $\mathrm{p}$.

\section{RELIABILITY CENTERED MAINTENANCE}

Because of inaccessibility of the data from operation of railway vehicles (but in general all machines) it is not possible to use fully the methods of a posteriori reliability for creation of con- 


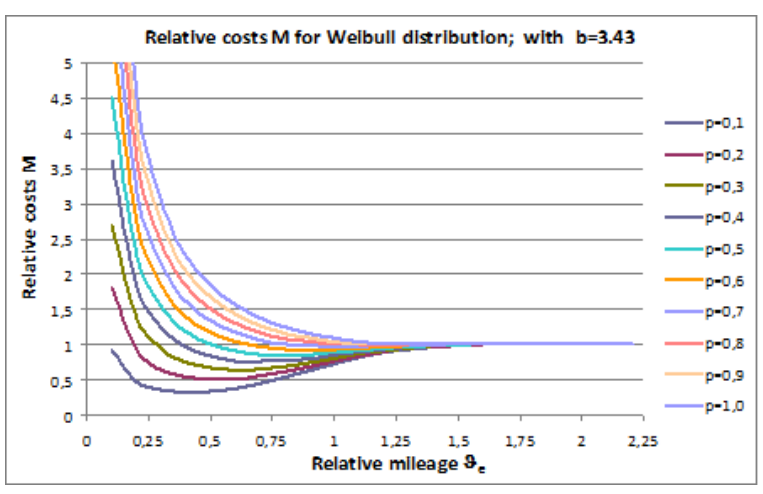

Fig. 4. Course of relative costs $M$ for Weibull probability distribution with $b=3.43$

tent and extent of maintenance. So for the determination of content and extent of maintenance of bogie series GP 200 we used the method RCMII $[7,9,10,11]$.

\section{Bogie GP 200}

Main technical parameters of the bogie (Fig. 5):

- Wheel base $2600 \mathrm{~mm}$,

- Wight of the bogie (depending on variant) in the range of $5400-6035 \mathrm{~kg}$,

- Years of manufacture $1984-1990$,

- Rail gauge $1435 \mathrm{~mm}$,

- Minimum curve radius R $150 \mathrm{~m}$,

- Maximum speed $120 \mathrm{~km} / \mathrm{h},(200 \mathrm{~km} / \mathrm{h}$ for special variants),

- Wheel sets with solid wheels, $0920 \mathrm{~mm}$,

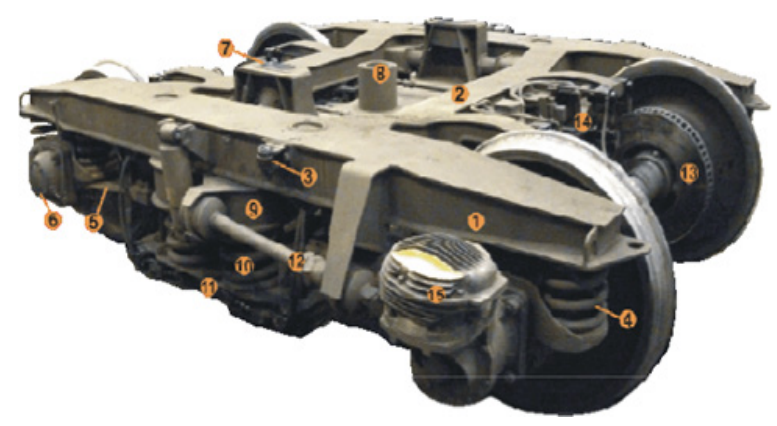

Fig. 5. Bogie GP 200: Bogie frame (1 - longitudinal beam, 2 - crossbeam, 3 - stop for reduction transverse clearance in curve), journal box and suspension (4 - primary suspension spring, 5 - longitudinal wheel set link, 6 - earthing FROST), support of the vehicle body on a bogie ( 7 - side slide bearing, 8 - silent block for kingpin), secondary suspension (9 - bolster, 10 - secondary suspension springs, 11 - support of secondary suspension, 12 - longitudinal link of bolster, brake (13 - brake disc, 14 - brake unit)
- Minimum diameter of worn wheel $0854 \mathrm{~mm}$,

- Diameter of disc brake $0590 \mathrm{~mm}$,

- Max load on the bogie $235 \mathrm{kN}$,

- Bogies on wagons without central electric supply are equipped with 3-phase alternator driven from axle.

We have worked-out FMEA of bogie series GP 200 in the software APIS PRO 6.0 with the criticality analysis, including functional and failure nets. (The software is being used at the Department of transport and handling machines).

In total 178 failure modes of bogie GP 200 were analysed (faults - formally failure causes and consequences) using the RCM II decision sheets. From the analyses it concluded that during the functional loss caused by failure under operational conditions (evaluation in column $\mathrm{H}$ - Figure 6) the failure is evident (No Hidden) in 57 cases, $(32.02 \%)$ and hidden failure is in 121 cases $(67.98 \%)$.

From evident failures, 56 function failures $(98,25 \%)$ can cause injury or death (failures in column S - Safety) and 1 function failure (1.75\%) can cause operational consequences (column 0 in figure 6). The overall overview of failure modes distribution is in Fig. 6.

Further on, within the RCM decision sheets the preventive tasks were analysed in column H1/ $\mathrm{S} 1 / 01 / \mathrm{N} 1$ used for an analysis whether appropriate task for technical condition identification can be used, which enables early prediction of failure occurrence and by that avoiding its consequences. We found 162 tasks technically feasible (suitable) for prediction $(92.6 \%)$ and 13 which are not technically feasible $(7.4 \%)$ out of 175 failures considered in this analysis.

Preventive tasks in column $\mathrm{H} 2 / \mathrm{S} 2 / 02 / \mathrm{N} 2$ that are used for analysis whether it is possible to find suitable restoration tasks that would prevent fail-

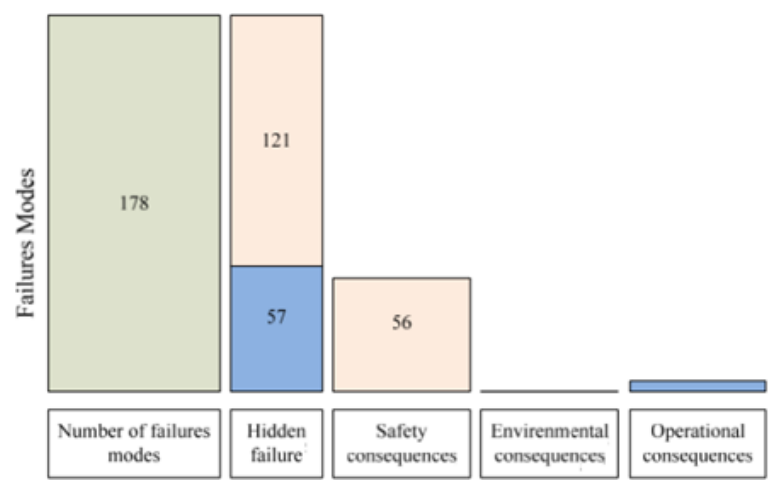

Fig. 6. Distribution of failure modes of Bogie 200 


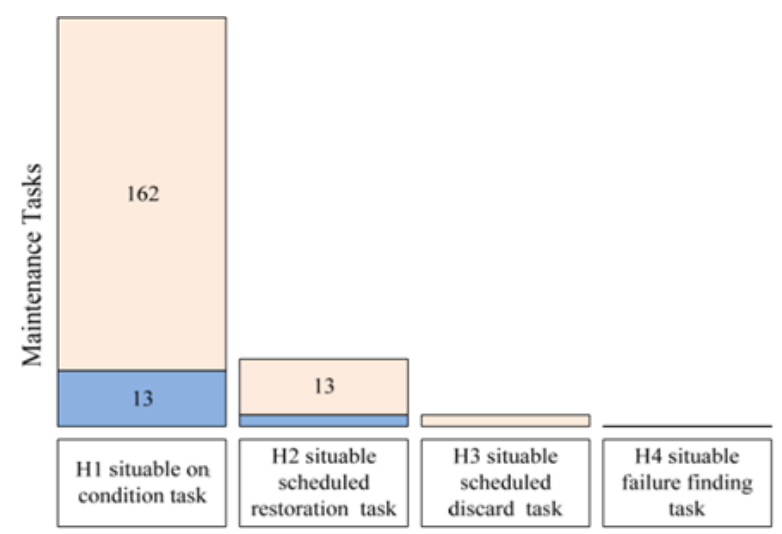

Fig. 7. Distribution of maintenance tasks for Bogie GP 200

ure occurrence - out of 14 tasks 12 are feasible $(85,7 \%)$ and 2 are not feasible $(14,3 \%)$.

Preventive tasks in column $\mathrm{H} 3 / \mathrm{S} 3 / 03 / \mathrm{N} 3$, used for analysis of possibility to find suitable discard task that prevents failure occurrence was found in 2 cases as technically feasible.

In complementary questions in column $\mathrm{H} 4$ in RCM II decision sheet, no technically feasible task that is reasonable to carry it out was found.

3 failure modes, out of total 178 recognised, require different solutions and they were not considered in this analysis - Fig. 7.

Based on FMEA analysis of bogie GP 200 and evaluation of RCM sheets for individual components of the bogie GP 200, the technical evaluation points in some case at insubstantiality of maintenance tasks during predetermined maintenance carried out according to current regulations given by the operator of railway vehicle with bogie GP 200. According to the FMEA and RCM II evaluation, safe operation ot boogie GP 200 provides space for extending the time be- tween executions or maintenance tasks. This fact may significantly enable better utilisation of components of bogie GP 200 to their limit values and from the economic point of view can reduce the costs for maintenance of the bogie.

\section{CONCLUSIONS}

Reliability, in the general concept, is seen as stability of performance over a specified time and under given conditions of use. Dependability, in the narrower concept (Fig. 9) is an emergency as determined by three factors: reliability, maintainability and maintenance support. With the addition of security are referred to as RAMS [1, 3, 4, 5].

Great attention is dedicated to reliability and availability, maintenance, evaluation, maintainability, less maintenance and maintenance support. The big downside is the assessment of these country-ness posteriori. Built negative values in the product cannot improve maintenance.

This loophole should largely eliminate maintainability studies in the pre and post-stage smallscale product design and its relationship to other tasks to ensure maintainability and maintenancetion. Maintainability studies objectives are:

- manage the design decision;

- predict maintainability quantitative characteristics of the object;

- identify any changes in the building design or requirements, or both, if they are necessary to meet the operational requirements under the current restrictions.

Maintainability studies must be developed and combined with the design process, so that you hovel-established system operational requirements. To ensure the satisfaction of those require-

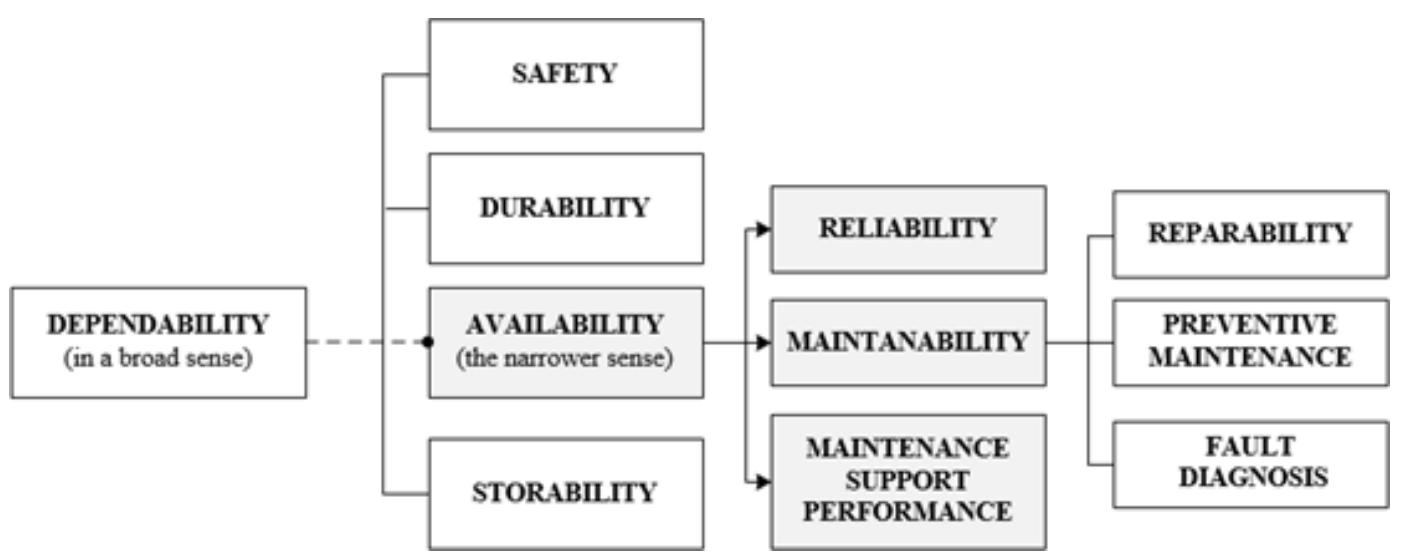

Fig. 8. Dependability in the narrow and broadest definition 
ments, Maintainability studies carried out during all stages of design. Their results should provide input into decisions about design.

Maintainability studies form part of the program maintainability. Its aim is to ensure that supplied building meets the requirements for maintainability.

Maintainability analysis, which is an integral part of studies, maintainability, is why I-defining operational requirements for qualitative and quantitative requirements for maintainability, and design criteria. Maybe this direction will produce results for improved maintenance.

\section{Acknowledgements}

This article was made under support projects KEGA 037ŽU-4/2014 - The Development of Complex Interactive Educational Portal for Support the Teaching of CNC Production Machines Programming.

\section{REFERENCES}

1. Stuchlý V. and Poprocký R. Maintenance of machines and equipment (Údržba strojov a zariadení). Žiline, Žilinská univerzita, 2014, 359.

2. Čuboňová N. and Kuric I. Software program for training of control system sinumerik $840 \mathrm{D}$. Academic Journal of Manufacturing Engineering, 9(3), 2011, 80-83.

3. Jasiulewicz-Kaczmarek M. Sustainability: orientation in maintenance management-theoretical background. In: P. Golinska et al. (eds.): Eco-Pro- duction and Logistics. Emerging Trends and Business Practices, Springer - Verlag Berlin Heidelber, 2013, 117-134.

4. Jasiulewicz-Kaczmarek M. Sustainable maintenance - the next generation of maintenance management. International Conference on Innovative Technologies, Budapest, 10-12.09.2013, 193-196

5. Rudawska A., Čuboňová N., Pomaranska K., Stančeková D. and Gola A. Technical and organizational improvements of packaging production process, In: Advances in Science And Technology-Research Journal, 10, 2016, 182-192.

6. STN EN 60300-3-11 (01 0690) Manazerstvo spol'ahlivosti. Cast' 3-11, Navod na pouzivanie. Udrzba zamerana na bezporuchovost, Ucinnost Odl., 5, 2010.

7. Stuchly V. and Grencik J. Calculation of preventive maintenance tasks using RCM method. Euromaintenance 2010 Conference, Fiera di Verona - Italy, 207-209.

8. Stuchly V. and Grencik J. Calculation of preventive maintenance tasks using RCM method (Výpočty intervalov preventívnych údržbových úloh v metóde RCM) Euromaintenance XX International Maintenance Conference, 2010, Fiera di Verona, Italy.

9. SAE JA1011: Evaluation Criteria For RCM Processes, surface vehicle/aerospace standard, sae ja1011, 2009, http://www.sae.org, 2009.

10. Moubray J. Reliability centred maintenance II. Industrial Press, New York NY, United States, 2002.

11. Zssk V66: Predpis pre opravy zeleznicnych voznov, Praha, NADAS, 1976 (platnosf od 1.7.1976 a upraveny 19.6.2001). (railway mainteance regulation). 